\title{
Designing Multiband and Broadband Antenna for 3G Mobile Handsets
}

\author{
Tran Minh Tuan ${ }^{1}$, Luu Van Hoan ${ }^{2}$ \\ ${ }^{1}$ National Institute of Information and Communications Strategy \\ Ministry of Information and Communications (MIC) \\ Email:tm_tuan@mic.gov.vn \\ ${ }^{2} \mathrm{~K} 15 \mathrm{D} 1$, University of Engineering and Technology, \\ Vietnam National University, Hanoi (UET-VNUHN) \\ Email: luuhoannd@gmail.com
}

\begin{abstract}
This paper concentrates on studying, designing and manufacturing a broadband microstrip antenna to be able to operate within many frequency bands. Antenna is used for 3G mobile handsets operating within GSM, UTMS, and WLAN bands. This antenna is made from FR4-epoxy substrate having $\varepsilon_{\mathrm{r}}=$ $4.4, \mathrm{~h}=0.8 \mathrm{~mm}$ (thickness). It is designed at $900 \mathrm{MHz}$ and $2000 \mathrm{MHz}$ frequencies. It has folded structure and includes three branches: two resonant branches and a tuning branch which are fed by $\mathbf{5 0} \Omega$ microstrip line.
\end{abstract}

Keywords: Microtrip Antenna; Broadband Antenna; Multiband Antenna

\section{INTRODUCTION}

In recent years, wireless communication has been developed so rapidly and requirement for the compact mobile handsets is high.

To satisfy the demands of reducing mobile handset size, antenna on the terminals needs to reduce as well. Microstrip antennas have many interesting advantages such as small dimensions, easy to attach on the terminals, and subsequently they will be the best choice to satisfy above designing demands.

Narrowband is an inherent property of microstrip antennas and broadband is normally a demand with real applications today, especially for $3 \mathrm{G}$ broadband mobile networks. Therefore, size reducing and broadband capability are two main design trends for real applications of microstrip antennas. These trends attract much attention of antenna's designers. Many significant innovations in designing compact microstrip antennas with properties such as broadband, multiband, operating with both vertical polarization and horizontal polarization, circular polarization and higher gain have been reported during recent years.

In this paper, designing and manufacturing of planar monopole microstrip antenna with 2D structure [1] and [2] is concentrated. By selecting an antenna structure and carefully adjusting the parameters, we can achieve multi-resonant and broadband properties, which are able to satisfy designing demands of applications in $3 \mathrm{G}$ wireless network.

\section{DESIGNING AND SIMULATING ANTENNA}

A planar monopole antenna [3] includes a rectangular radiator after being cut by a winding slot to make three branches, where two of which are resonant branches and the other one is a tuning branch. Antenna is printed on a FR4-epoxy substrate and is fed by a $50 \mathrm{Ohm}$ microstrip line. This antenna can be used for GSM, UTMS and WLAN bands with VSWR below 2.5.

An overview of this antenna is as in Fig. 1. The antenna surface area is $75 \times 36 \mathrm{~mm}^{2}$. The antenna structure includes three parts: radiator, broadband impedance matching component and $50 \Omega \mathrm{hm}$ microstrip line. Radiator has an area of $15 \times 36 \mathrm{~mm}^{2}$ printed on a surface of substrate. On the other surface 
of substrate, ground plane (GND) is printed with an area of $60 \times 36 \mathrm{~mm}^{2}$.

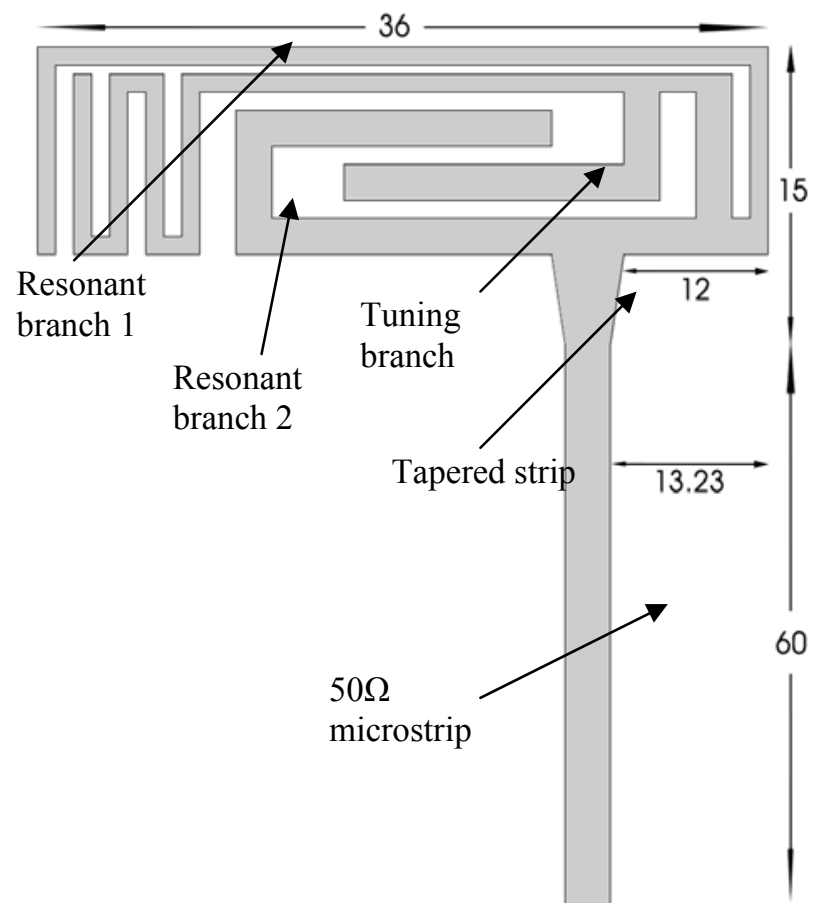

Figure 1: Overview of the antenna.

FR4-epoxy substrate is quite cheap material available on the market and is often used to make print circuit board.

Original radiator has rectangular shape fed by a $60 \mathrm{x}$ $1.54 \mathrm{~mm}$ microstrip line. To achieve multi-resonant property, we cut a winding slot on original radiator to make three branches, where the first resonant branch is longer, the second is shorter and the tuning branch (third branch) with detail dimensions as in Fig 2.

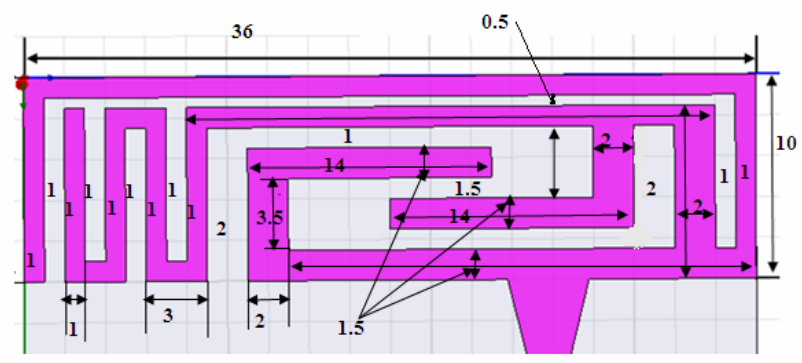

Figure 2: The radiator of the antenna.

The length of the first resonant branch from feeding point to the its end is about $75 \mathrm{~mm}$. This value is approximate to $1 / 4$ of the wavelength at the $900 \mathrm{MHz}$ in the free space [4] and [5].

We need to note that resonant frequency depends on both the length and the width of the end. In the same way, the length of the second resonant branch from feeding point to its end is about $35 \mathrm{~mm}$, approximately to $1 / 4$ of the wavelength at the $2 \mathrm{GHz}$.



Figure 3: E field simulation.

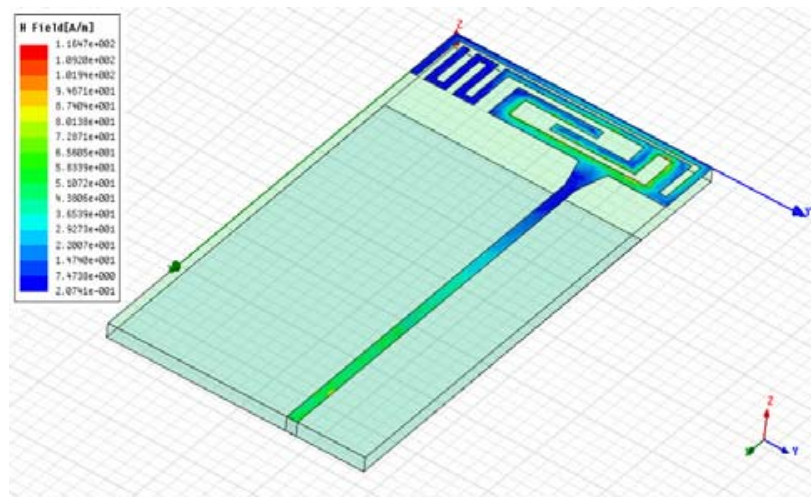

Figure 4: H field simulation

The tuning branch is added to reach demanded bandwidth. By carefully tuning the dimensions and position of the tuning branch, the basic resonant modes and higher levels of the first resonant branch can be adjusted to demanded frequency.

As the simulation data, resonant frequency of the basic mode is reduced from $900 \mathrm{MHz}$ to $850 \mathrm{MHz}$. With higher level mode, resonant frequency is changed from more than $3 \mathrm{GHz}$ to about $2.3 \mathrm{GHz}$. As a result, antenna with all three branches can operate in all three bands: GSM, UTMS, and WLAN. 
The broadband impedance matching component is a trapezium microstrip line with small bottom of 1.54 $\mathrm{mm}$, big bottom of $4 \mathrm{~mm}$ and height of $5 \mathrm{~mm}$. This is a triangular tapered line.

The simulation was carried out by Ansoft HFSS 9.1 software. The simulation results of $\mathrm{E}$ field and $\mathrm{H}$ field are shown in Fig. 3 and Fig. 4 respectively.

Figure 5 shows the result for simulated return loss $\mathrm{S}_{11}$ of antenna with all three branches.



Figure 5: Simulated return loss $S_{11}(d B)$ of the antenna.

With return loss $\mathrm{S}_{11}=-8 \mathrm{~dB}$, similar to VSWR $($ Voltage Standing Wave Ratio $)=2.5$, we can see that antenna with the tuning branch resonates around 850 $\mathrm{MHz}, 2160 \mathrm{MHz}$ and $2380 \mathrm{MHz}$.

When having the third branch, the resonant frequency of the antenna is tuned to around the three above bands and bandwidth is nearly enough to cover all three bands' demand (GSM, UTMS, and WLAN).

Figure $6,7,8$ below show the radiation patterns in XOY, YOZ, XOZ planes.

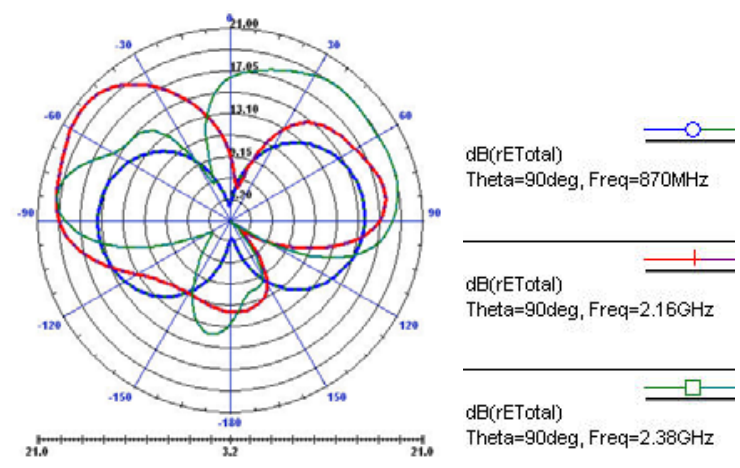

Figure 6: XOY plane of simulated radiation pattern.

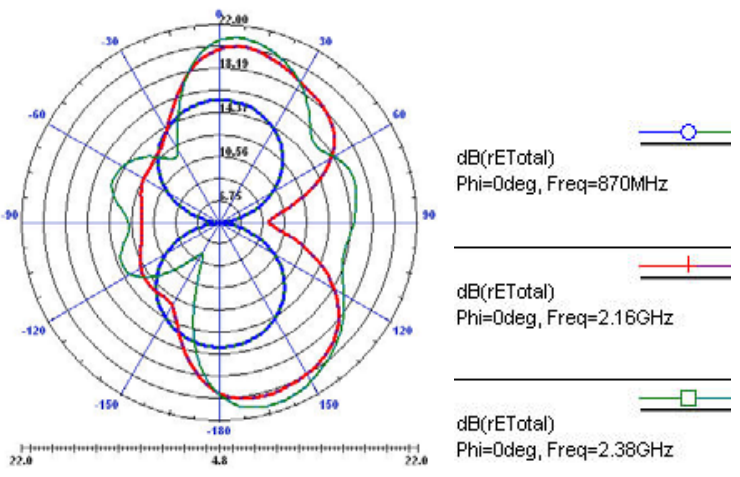

Figure 7: XOZ plane of simulated radiation pattern.
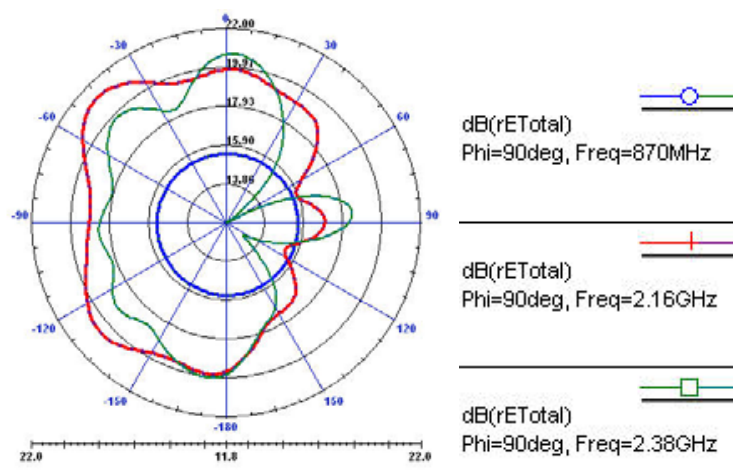

Figure 8: YOZ plane of simulated radiation pattern.

\section{MEASUREMENT RESULTS}

Figure 9 shows measurement results for return loss.

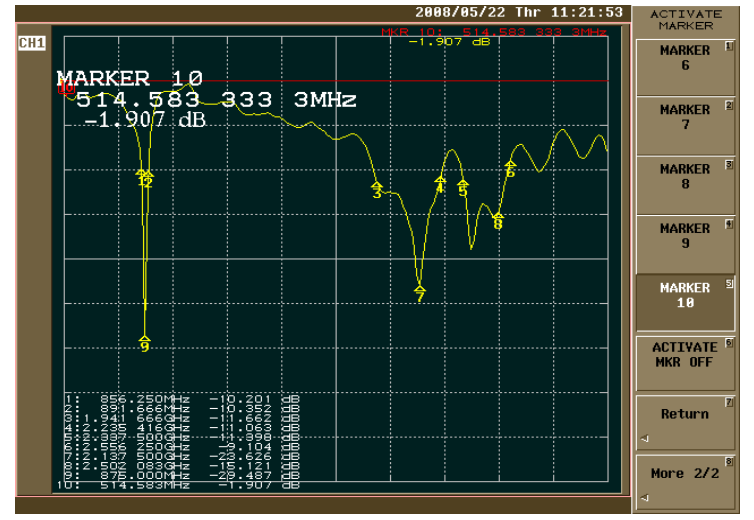

Figure 9: Measured return loss $S_{11}(d B)$ of the antenna.

\begin{tabular}{|c|c|c|}
\hline Band & $\begin{array}{c}\text { Resonant } \\
\text { frequency }\end{array}$ & $\begin{array}{c}\text { Bandwidth } \\
\text { VSWR }=\mathbf{2 . 5}\end{array}$ \\
\hline GSM & $850 \mathrm{MHz}$ & $825-926 \mathrm{MHz}$ \\
\hline UMTS & $2160 \mathrm{MHz}$ & $1530-2530 \mathrm{MHz}$ \\
WLAN & $2380 \mathrm{MHz}$ & \\
\hline
\end{tabular}

Table I: The results of the simulation 
With $\mathrm{S}_{11}=-8 \mathrm{~dB}$, VSWR is similar to 2.5 , bandwidth from Network Analyzer for respectively bands are as follow Table II.

\begin{tabular}{|c|c|c|}
\hline Band & Frequency range & Bandwidth \\
\hline GSM & $830-915 \mathrm{MHz}$ & $85 \mathrm{MHz}$ \\
\hline UMTS & $1941-2235 \mathrm{MHz}$ & $294 \mathrm{MHz}$ \\
WLAN & $2337-2556 \mathrm{MHz}$ & $219 \mathrm{MHz}$ \\
\hline
\end{tabular}

Table II: Band width as mesurement

Figure 10 shows measurement result and simulation result. The measurement result and simulation result are quite agreeable to each other. However the achieved bandwidth has not completely covered all three demanded bands, especially for GSM band.

Figure 11 shows the real shape of the antenna. It is very compact with the size of the model $3 \mathrm{G}$ mobile handset.

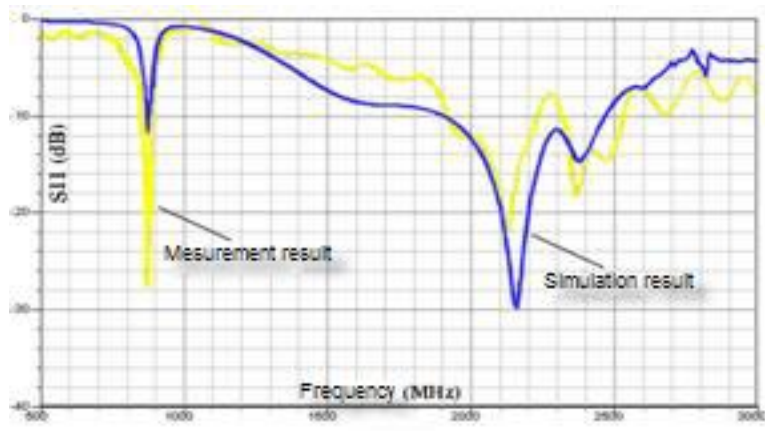

Figure 10: Measurement result and simulation result



Figure 11: The real shape of the antenna.

\section{CONCLUSION}

The designed antenna can completely be able to apply for 3G (operating on multiband and broadband) in GSM, UMTS and WLAN bands. However, in the future, some parameters of the antenna should be adjust so that it has better performance in term of the bandwidth.

\section{REFERENCES}

[1] A. Phan, "Antenna Theory and Technique", Science and Technical Press, Hanoi, 2000, pp.

[2] A. Phan and T. M. Tran, "On a method of formation of surface wave structures using for strip antennas", Antennas and Propagation Society International Symposium, 2001 IEEE, vol.3, pp.720.

[3] C. A. Balanis, "Antenna Theory - Analysis and Design”, John Willey \& Son, INC, Second Edition, 1997.

[4] D. M. Pozar, "Microwave Engineering", John Willey \& Son, INC, Second Edition, 1998.

[5] R. Garg, Prakash Bhartia, I. Bahl, A. Ittipiboon, "Microstrip Antenna Design Handbook", Artech House, 2001.

\section{AUTHORS' BIOGRAPHIES}



Tran Minh Tuan (Ph.D) was born in Hanoi - Vietnam in 1970 . He received the B.E degree and M.E degree in Satellite Communications from Moscow Institute of Technology in Russia in 1994 and in 1995, respectively. In 2004, he received Ph.D degree in antenna and radiowave propagation in Hanoi University of Technology, Vietnam. Now he is working in National Institute of Information and Communications Strategy, Ministry of Information and Communications of Vietnam.

His current research interests include: slow-wave structures, slotted, leaky-wave and microstrip antennas, radiowave propagation, CAD software for slow-wave structures, slotted, leaky-wave and microstrip antennas etc. 
Research, Development and Application on Information and Communication Technology

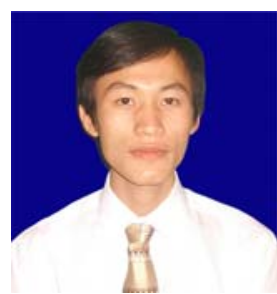

Luu Van Hoan was born in

01/11/1985 in Nam Dinh province. He

received B.S degree in Wireless

Communication in University of

Engineering and Technology,

Vietnam National University, Hanoi

(UET-VNUHN) in 2008. Currently,

he is studying M.S degree at UET-VNUHN.

His main interests include Microstrip Antennas; Simulation

of the Wireless Channel using Matlab. 